\title{
Nuevos actores en el ecosistema del libro: bookstagrammers argentinas y la recomendación digital de literatura contemporánea
}

\begin{abstract}
Diego Vigna
Centro de Investigaciones y Estudios sobre Cultura y Sociedad (CIECS), CONICET y Universidad Nacional de Córdoba.

diegovigna@unc.edu.ar
\end{abstract}

Lucía Coppari

Instituto de Estudios en Comunicación, Expresión y Tecnología (IECET), CONICET y Universidad Nacional de Córdoba. luciacoppari@gmail.com

Fecha de finalización: 30 de julio de 2020. Recibido: 26 de agosto de 2020 .

Aceptado: 26 de noviembre de 2020 DOI: https://doi.org/10.26422/aucom.2020.0902.vig

\section{Resumen}

Los formatos de publicación web, como las redes sociales, han introducido cambios evidentes en las maneras de producir, hacer circular y leer obras literarias. En Argentina, y en el resto del mundo, las cuentas en Instagram dedicadas a la lectura y recomendación de libros crecen a ritmo acelerado (lo que dio lugar a una nominalización y a la ampliación del mercado), como también la cantidad de usuarios vinculados, lo que resulta en la formación de comunidades informales que, en ocasiones, trascienden la actividad online. Este trabajo propone un abordaje descriptivo y analítico de cuatro cuentas de Instagram dedicadas a la recomendación de libros (bookstagrammers) que producen contenidos basados en sus propios acopios de lecturas. Los resultados dan cuenta de un distanciamiento de las rutinas de la crítica literaria asociada a la herencia de publicaciones impresas en Argentina, y un acercamiento a herramientas de difusión y consumo cultural que propician la caracterización de interacciones desplegadas entre recomendadores, lectores, autores y también editores.

Palabras clave: consumo cultural, formatos de publicación digitales, recomendaciones literarias, bookstagrammers, ecosistema del libro.

\section{New players in the book ecosystem: Argentine bookstagrammers and literary recommendations in a digital space}

\section{Abstract \\ Online publication formats, such as social media, have clearly transformed how literary works are produced, circulated, and read. In Argentina, as in the rest of the world, Instagram accounts}


dedicated to reading and recommending books are growing at an accelerating rate. (This, in turn, has allowed for the nominalization and expansion of the market.) The number of users who follow these accounts has likewise grown, leading to the rise of informal communities that, in some cases, transcend their online origins. This paper presents a descriptive and analytical assessment of four Instagram accounts (four bookstagrammers) that offer book recommendations as well as contents based on their own libraries and reading histories. Our results show how these accounts distance themselves from the practices of literary criticism, associated with the heritage of print publications in Argentina; while adopting tools for the distribution and consumption of culture, which help characterize the interactions between recommenders, readers, authors, and publishers.

Keywords: cultural consumption, digital publication formats, literary recommendations, bookstagrammers, book ecosystem.

\section{Novos atores no ecossistema do livro: bookstagrammers argentinas e a recomendação digital da literatura contemporânea}

\section{Resumo}

Os formatos de publicação na Web, como as redes sociais, introduziram mudanças óbvias nas formas de produção, circulação e leitura de obras literárias. No mundo, e também na Argentina, as contas do Instagram dedicadas à leitura e recomendação de livros estão crescendo em ritmo acelerado (o que levou a uma nominalização e expansão do mercado), assim como o número de usuários vinculados, o que resulta na formação de comunidades informais que às vezes transcendem a atividade online. Este trabalho propõe uma abordagem descritiva e analítica de quatro contas do Instagram dedicadas à recomendação de livros (bookstagrammers) que produzem conteúdo a partir de suas próprias coleções de leituras. Os resultados mostram um distanciamento das rotinas de crítica literária associadas à herança das publicações impressas na Argentina, e uma abordagem de ferramentas de divulgação e consumo cultural que promovam a caracterização das interações implantadas entre recomendadores, leitores, autores e também editores.

Palavras-chave: consumo cultural, formatos de publicação digital, recomendações literárias, bookstagrammers, ecossistema do livro.

\section{Introducción}

Hace ya dos décadas que, en el contexto argentino, los formatos de publicación virtuales que emergieron con internet -entre ellos, las cuentas en redes sociales como Facebook, Twitter, Instagram y Youtube- introdujeron cambios evidentes y relevantes en las maneras de producir, hacer circular y leer obras literarias. Algunos estudios han abordado de manera específica estos cambios, sobre todo en el polo de la producción: qué hacen los escritores con sus publicaciones en estas plataformas digitales que tienen a su disposición y en las que intervienen de diversas formas (Rodríguez Ruiz, 2018; Vanoli, 2019; Vigna, 2014). En términos generales, si bien la producción de libros digitales en Argentina se estancó -con algunas salvedades coyunturales- en la última dé- 
Austral Comunicación

Volumen 9, número 2 (Diciembre de 2020): 349-373. ISSN 2313-9129

cada, ${ }^{1}$ las redes sociales se han consolidado como "vidrieras" donde poner en escena el yo público (Groys, 2014), colocar, "testear" y promocionar las producciones, ampliar su circulación y también como espacios de interactividad mediada por algoritmos entre escritores, editores, libreros, periodistas y lectores.

Por lo tanto, no solamente se diversificaron soportes y canales de difusión, sino también formas de publicidad, interacción y repercusión literaria. En este sistema de medios denominado hipermediático por Carlón (2015), o de medios conectivos por Van Dijck (2016), se hace visible la multiplicación de variantes de enunciación y experimentación a raíz de las condiciones para la producción de contenidos a gran escala y, con ello, una serie de transformaciones en la circulación de la producción literaria y editorial nacional. En particular, uno de los fenómenos que más atención ha reclamado en los últimos años es la proliferación de booktubers y bookstagrammers: usuarios de dos redes sociales específicas -Youtube, en el primer caso, e Instagram, en el segundo- que leen, reseñan y recomiendan libros a través de cuentas tanto personales como administradas por proyectos colectivos. En algunos casos, estas intervenciones y recomendaciones sobre libros son auspiciadas por algunas editoriales, distribuidoras o librerías; en otros, se trata simplemente de usuarios que, a caballo de las gramáticas de publicación e interacción de dichas plataformas, gustan de la lectura, la promueven y orientan, haciendo uso productivo de los recursos hipermediales.

En esta línea, la pregunta que orienta el desarrollo del trabajo es cómo se vincula la aparición de nuevos actores en las dinámicas y los procesos concernientes al ecosistema del libro en Argentina, a partir del uso extendido de formatos y plataformas digitales en red, con los mecanismos y vehículos históricos de repercusión crítica, circulación y comercialización de las obras literarias impresas. A su vez, de este interrogante surge otro subsidiario: de qué formas ha impactado el trabajo de bookstagrammers en Argentina en los modos de sociabilidad online y offline que asume la producción literaria y la comercialización de libros. Para aproximarnos a posibles respuestas, ponemos énfasis en el abordaje de transformaciones, tensiones y puntos de contacto entre las rutinas de producción, crítica y difusión de la literatura que, a lo largo del siglo XX, fueron desarrolladas por revistas, suplementos culturales y espacios de crítica cultural y literaria (en los que se nucleaban a grupos intelectuales y artísticos con plumas especializadas y, en ciertos casos, líneas programáticas de intervención estética, cultu-

\footnotetext{
Según el último informe de la Cámara Argentina del Libro (2020), la proporción de novedades en soporte digita se ha mantenido relativamente constante desde 2012, con valores que rondan entre el 17 y el $19 \%$. El periodo de Aislamiento Social, Preventivo y Obligatorio decretado durante la pandemia originada por el COVID-19 en Argentina (a partir del segundo trimestre de 2020) marca, sin embargo, un aumento en el lanzamiento de novedades en soporte digital.
} 
ral o ideológica), ${ }^{2}$ y las propuestas aquí analizadas de bookstagrammers, profesionales o amateurs, que toman la iniciativa de producir contenidos basados en sus propios acopios de lecturas. Nuestra hipótesis es que estos nuevos actores dedicados a desarrollar canales interactivos y cotidianos de recepción y difusión de libros despliegan una oferta discursiva que interpela y se distancia, al menos parcialmente, de la tradición de publicaciones que abordaron la crítica literaria y cultural hasta la primera década de este siglo.

En el mundo, y también en Argentina, las cuentas en redes sociales dedicadas a la lectura y recomendación de libros vienen creciendo a un ritmo acelerado -lo que dio lugar a su nominalización específica y a la ampliación del mercado a su alrededor- $y$, en paralelo, la cantidad de usuarios que las "siguen", entre los cuales se forman comunidades o colectivos (Verón, 2013) que, en ocasiones, trascienden la actividad online. Este trabajo propone un acercamiento descriptivo y analítico y se circunscribe al abordaje de cuatro cuentas que bookstagrammers argentinas administran en la red social Instagram. La labor empírica se ofrece a partir de la aplicación de categorías de análisis especificadas en el apartado 3, que se sostienen teórica y metodológicamente sobre la caracterización de las plataformas de redes sociales digitales (profundizaremos el caso de Instagram) y los colectivos de usuarios-lectores.

La estructura del trabajo se compone de la siguiente manera: 1) las referencias teóricas y conceptuales que sostienen el análisis, centradas en las características históricas y actuales del circuito del libro impreso en Argentina, complementadas por la naturaleza del objeto de estudio (rasgos específicos de los objetos digitales); 2) el diseño metodológico aplicado, con sus premisas centrales; 3 ) los resultados de la descripción y el análisis de la cuentas seleccionadas; 4) la discusión, que expone los elementos más importantes del análisis en la contextualización del problema; y 5) las conclusiones.

\section{Marco teórico y conceptual}

Aquí se definen los lineamientos conceptuales que encuadran el análisis y la discusión. En primer término, se presentan las transformaciones en la circulación literaria y editorial con el advenimiento de internet y los soportes y formatos digitales. A continuación, se examinan de manera específica las repercusiones sobre el campo literario argentino. Luego, el foco se circunscribe al fenómeno de la edición independiente en el

\footnotetext{
Mencionamos algunas publicaciones impresas que han vertebrado, desde la segunda mitad del siglo XX hasta entrados los años 2000, los espacios de crítica, debate y difusión de la producción literaria, cultural e intelectual en Argentina: Contorno (1953-1959); Los libros (1969-1976); El ornitorrinco (1977-1986); Crisis (1973-1976, 19861987 y actualidad); Babel (1988-1991); Punto de vista (1978-2008); además de suplementos culturales de medios de prensa como Radar y Radar Libros (Página/12), N (Clarín), diario La Nación y diario Perfil, entre tantos otros. Quedan fuera notables y numerosas publicaciones de distintos perfiles y posiciones estéticas e ideológicas. Estas menciones solo buscan ejemplificar y contextualizar el sector al que nos referimos.
} 
Austral Comunicación

Volumen 9, número 2 (Diciembre de 2020): 349-373. ISSN 2313-9129

país y la incidencia del paradigma digital. En función de este recorrido, por último se introduce una caracterización de las plataformas conocidas como redes sociales y sus modalidades de uso.

\section{La circulación literaria en la Argentina reciente: autores, lectores, editoriales, soportes y sociabilidades}

Para comprender el fenómeno de la recomendación y difusión de libros en redes sociales es preciso examinar la circulación literaria y editorial en la Argentina reciente. Enmarcamos el análisis desde fines del siglo pasado hasta la actualidad para dar cuenta de la convivencia de soportes como un elemento central en la evolución del campo literario y editorial, es decir, la presencia consolidada de internet y de los formatos digitales en las dinámicas de producción/circulación de literatura, históricamente atada a la cultura impresa. Este fenómeno tuvo como bisagras la accesibilidad a dispositivos "inteligentes" por parte de los actores del campo (también usuarios) -como teléfonos móviles y computadoras- y la popularización de las interfaces.

Los soportes y formatos digitales posibilitaron la autoedición (escribir, editar, publicar sin mediaciones) y la reducción de costos para la administración de espacios personales o colectivos virtuales (creación y administración de bitácoras o cuentas en redes sociales). Cualquier autor, lector, editor o agente implicado en el proceso de producción/circulación literaria pudo "alfabetizarse" en el uso de estos medios y definir estrategias de distinción gracias a la accesibilidad y usabilidad de los softwares.

Durante las últimas dos décadas, ha sido exponencial el crecimiento en la cantidad de usuarios que producen contenidos en la web (Carlón, 2015) y que, por la evolución de los procesos conectivos, establecen y expanden instancias de interacción y sociabilidad en torno al mercado editorial y la producción literaria. A condición, entre otras, del desarrollo y la disponibilidad de estas tecnologías, la edición independiente creció significativamente, dando lugar a una serie de cambios en la producción y circulación.

A continuación se realiza un repaso de la irrupción de las pantallas en red y de los movimientos en la edición independiente dentro del periodo delimitado.

\section{La irrupción digital en el campo literario argentino}

Desde la popularización en vastos sectores sociales del uso de internet y de la consecuente cultura interactiva, la herencia textual se ofrece tanto en papel como en la omnipresencia de las pantallas. La producción escrita fue complementada por elementos en origen restringidos al universo audiovisual, como la priorización del diseño -relacionado con lo que Boris Groys (2014) llamó "diseño de sí" (p. 33)- en lo ofrecido a un público (Botto, 2012). A su vez, el desarrollo de medios conectivos (Van Dijck, 
Diego Vigna, Lucía Coppari

Nuevos actores en el ecosistema del libro: bookstagrammers argentinas y la recomendación digital de literatura contemporánea

2016) hace décadas que se materializa en formatos, plataformas y arquitecturas hipertextuales e hipermediales que están a disposición de quien decida administrarlos, lo que amplió las posibilidades de acceder a lo producido de primera mano por escritores y a la oferta de sellos editoriales, además de generar variantes de vinculación y comercialización entre editores y lectores y de permitir la circulación incesante de imágenes y textos. Difuminando los límites entre producción e interacción, el llamado "ecosistema de medios conectivos" propició una concepción de la velocidad (Pariser, 2017; Van Dijck, 2016) que se impone como valor en la lógica de producción, circulación y recepción de obras literarias.

Específicamente en Argentina, la web interactiva ${ }^{3}$ se convirtió en un espacio efervescente luego de la crisis política, económica y social de 2001. En dicho contexto, mientras críticos, intelectuales y académicos intentaban explicar el descalabro político y económico que impulsó a la acción colectiva y las organizaciones sociales frente a la coyuntura institucional, los actores del campo de producción/circulación literaria (narradores, poetas, editores, periodistas, libreros, lectores), inauguraron estrategias de visibilidad para la promoción de obras y la vinculación entre pares (Echeverría, 2009). En el contexto local, esas estrategias y nuevas rutinas se materializaron en la realización de festivales literarios, lecturas y ferias de libros, incluso en ámbitos restringidos. A su vez, estos cambios estuvieron acompañados por la asimilación del blog en tanto formato-bitácora concebida como personal y relacional (Wrede, 2005). Los blogs de escritores y las primeras revistas literarias digitales ${ }^{4}$ que usaron el formato tuvieron un pico de repercusión en el periodo 2003-2010 y llevaron a que formas discursivas establecidas comenzaran a repensarse debido a la flexibilidad e interactividad que propició el mundo virtual para los tiempos de la circulación impresa.

Según este enfoque, el blog abanderó la llamada "cultura participativa" en su asimilación específica de las rutinas de vínculos e influencias artísticas y literarias, que dio cuenta del potencial del formato para "alimentar conexiones y construir comunidades" (Van Dijck, 2016, p. 18). De allí surgieron instancias de vinculación entre autores y lectores (Vigna, 2014) al fusionar la producción, la edición y el feedback, ya que el blog popularizó la inserción de comentarios en las publicaciones originales de los autores.

En ese periodo también vieron la luz las redes sociales, junto a una cada vez mayor economía del lenguaje en la escritura, como afirma Van Dijck (2016, p. 20). El desarrollo, en sentido amplio, de la infraestructura conectiva de las redes sociales -que centralizó publicaciones, interacciones y comunidades en un solo espacio, a diferencia

\footnotetext{
Sitios web cuyas estructuras y contenidos dejaron de ser estáticos para permitir la participación, intervención e interacción de otros usuarios, que luego se sumaron a la evolución de las posibilidades semánticas de navegación y búsqueda, es decir, una "optimización" del rastreo y acceso a datos e información en internet.

4 Nación Apache, El interpretador, No Retornable, Los Asesinos Tímidos y Los Trabajos Prácticos, entre otros ejemplos de revistas digitales pioneras.
} 
de la blogosfera- llevó a algo más que al simple tránsito de formatos personales a plataformas: se pasó de "una cultura participativa a una cultura de la conectividad" (Van Dijck, 2016, p. 19).

\section{La edición independiente en contexto de crisis, expansiones y conectividades}

Si partimos de las condiciones sociales de producción editorial en Argentina, la información estadística disponible (Cámara Argentina del Libro, 2020) y los estudios sobre el libro y la edición coinciden en testimoniar la heterogeneidad y, a la vez, las desigualdades estructurales del campo, que no son ajenas a mercados de otros países latinoamericanos. Por desatención o por carecer de proyección a largo plazo, el Estado nacional ha venido oscilando en la implementación de políticas públicas sostenidas que, en términos generales, tiendan a equilibrar y a mejorar las condiciones para la actividad editorial, estimular integralmente la cadena de producción y comercialización del libro y favorecer el acceso democrático y federal, aspectos que cuentan como demandas históricas de buena parte del sector.

Durante la década del 90, las políticas neoliberales - privatizaciones, flexibilización laboral, apertura a los mercados internacionales y ausencia de incentivos a la producción- favorecieron el establecimiento de grupos editoriales transnacionales, que se consolidaron por el incremento de las importaciones y la reducción de los costos de producción. Varias empresas nacionales fueron adquiridas por estos capitales extranjeros y el campo evidenció transformaciones asociadas al cortoplacismo de la producción: proliferación de best sellers de gran tirada, irrupción de las cadenas de librerías, rápida obsolescencia de los títulos y estrategias de mercado a escala mundial (Botto, 2014).

Como se señaló anteriormente, después de la crisis de 2001, las editoriales independientes se multiplicaron y ganaron visibilidad. La organización colectiva entre escritores-editores ${ }^{5}$ y las tecnologías digitales impulsaron y acompañaron un boom editorial que tuvo como epicentro la ciudad y la provincia de Buenos Aires (principales polos editoriales), pero que también se registró en otras ciudades del país, como Rosario y Córdoba. Esta nominalización sobre el crecimiento de la edición independiente se fundó en los cambios de las condiciones de producción y circulación por la ampliación de la oferta, la experimentación sobre las materialidades y soportes y las variantes que surgieron en términos de publicidad y sociabilidad alrededor del libro.

Actualmente, al menos desde 2015, la cadena del libro y la actividad editorial en particular atraviesan una nueva crisis, en línea con los indicadores económicos del

El Asunto, Belleza y Felicidad, Eloísa Cartonera (todas de Buenos Aires), La Creciente (Córdoba), por mencionar algunos primeros exponentes. 
país. Las estadísticas revelan que si bien la cantidad de novedades publicadas se mantuvo relativamente constante, se produjo una considerable baja en ejemplares de libros impresos y, en el sector comercial, las pequeñas y medianas empresas registraron la caída más abrupta. El comercio exterior del libro presentó resultados deficitarios por el incremento de las importaciones. Los factores a considerar son múltiples, comenzando por la suba en los insumos y servicios para producir, atados a la devaluación de la moneda argentina y la inflación. El traslado de algunos de los costos de producción a los precios de tapa y la pérdida de poder adquisitivo de los lectores repercutieron en la baja de las ventas. Asimismo, la erogación en compras de libros por parte del Estado se vio notablemente disminuida. ${ }^{6}$

Las editoriales independientes continúan haciendo frente a estas condiciones de diferentes maneras: se profesionalizan, adaptando y consolidando sus planes de producción y comercialización, ampliando sus competencias técnicas, al tiempo que exploran modos creativos de inserción en el mercado de libros. La producción de ferias y encuentros copresenciales, en simultáneo con el desarrollo de la actividad en el entorno digital conectivo -páginas web, tiendas y bibliotecas digitales, cuentas en redes sociales- suman posibilidades de intercambio alrededor del libro: modos de circular, vender y socializar las obras en diferentes soportes y formatos. Incluso vienen propiciando la formación de colectivos y redes de trabajo autogestivo, ${ }^{7}$ en mayor o menor medida tributarias de las experiencias asociativas registradas después de 2001.

\section{Formatos y plataformas digitales: interfaces y modalidades de uso}

A la fecha, el número de cuentas que las redes sociales han captado exige atender a los modos de transmisión de datos que estos espacios propician y que han exacerbado lo que Stephenson (2003) llamó "nueva capa semiótica entre la gente y su máquina" (p. 63). Algo similar concluyó Debrah Ramsey (2018) al proponer una noción ampliada de "interfaz" que no se restringe solo a su función técnica, sino también a sus implicancias culturales. Como afirma Van Dijck (2016, p. 21), cada red social no es un espacio neutral que solo "hace circular" información, sino que desnuda las bases ideológicas de las web. Plataformas como Facebook o Instagram, por ejemplo, que pertenecen y son

\footnotetext{
Es necesario advertir que el desarrollo de este estado del arte, y la construcción de este marco teórico y conceptual, corresponden al periodo de indagación, descripción, análisis y redacción del trabajo, previo a la profundización de la pandemia por COVID-19 en Argentina.

Nos referimos a iniciativas muy diversas como "Malisia" (colectivo de editoriales independientes platenses, sello editorial y distribuidora que organiza la feria Edita); “Todo libro es político” (reunión de editoriales independientes para la participación en ferias, en sociedad con la distribuidora La Periférica); "La sensación" (feria de editoriales independientes nucleadas por los sellos porteños Blatt \& Ríos y Mansalva, en el espacio de la librería La Internacional Argentina); "La coop" (cooperativa conformada por sellos editoriales independientes con estructura de comercialización y distribución de títulos) o "Capítulo" (colectivo de editoriales independientes cordobesas que organiza ferias, charlas y presentaciones de libros).
} 
Austral Comunicación

Volumen 9, número 2 (Diciembre de 2020): 349-373. ISSN 2313-9129

administradas por la misma corporación, ${ }^{8}$ permiten conectarse con amigos, conocidos y desconocidos y fomentan una alfabetización en las rutinas de autopresentación (Manovich, 2017), así como también facilitan mecanismos para pertenecer a distintas comunidades. Las nociones de "promoción", "visibilidad" y "velocidad" han marcado una superación de la arquitectura de las redes sociales respecto a la blogosfera que imperó durante la primera década del siglo.

En plataformas como Facebook, Instagram, Youtube e incluso Twitter, que junto a las de mensajería (Whatsapp y FB Messenger) son las que recogen más usuarios e interacciones en Argentina (Shum, 2020), la intervención de los usuarios se produce desde gramáticas de utilización -vinculamos esta categoría al análisis de Manovich (2017) sobre el "lenguaje cultural" de una red social- que priorizan la circulación de imágenes al desarrollo textual, elemento base de la cultura letrada. Una vez "superado" el blog como formato de publicación e interacción, las redes sociales consolidaron núcleos centralizados de reproducción de contenidos, en los que un usuario enuncia y comparte a través de textos, imágenes, videos y herramientas hipertextuales.

\section{Materiales y métodos: delimitación del corpus y análisis de documentos e interacciones en Instagram}

Para analizar la actividad de bookstagrammers es necesario partir de algunas consideraciones metodológicas. Primero, que los contenidos abordados forman parte de la producción de posts en redes, que deben concebirse como documentos y, a la vez, como datos (Hui, 2017). Según este autor, y otros teóricos como Kallinikos, Aaltonen y Marton (2010), Hoskins (2017) y Ernst (2018), los objetos digitales (culturales o no) se diferencian en su composición de los analógicos porque incluyen, además del contenido, a las operaciones que permiten decodificarlos y volverlos accesibles a los usuarios. En los posts, los componentes visuales y textuales que propician sentidos e interpretaciones conviven con elementos hipermediales y operaciones propias de los protocolos de software; los contenidos (documentos) analizados nacen en pantallas y, en el caso que nos incumbe, no siempre remiten a obras, fragmentos textuales o citas de obras literarias (es decir, no replican expresiones propias de la cultura impresa), aunque surjan de la dinámica actual de producción literaria y editorial. Esto implica, a veces, analizar contenidos desde un encuadre relacional.

Hui (2017) define a los objetos digitales como datos que, en el ecosistema digital, "son fuentes de redes" (p. 88). De esta manera, son concebidos desde una ontología que los diferencia de los físicos (libros, revistas, folletos, etc.), en tanto exigen una técnica

\footnotetext{
8 En abril de 2012 se difundió en medios de prensa que Facebook había adquirido la plataforma Instagram por un monto cercano a los 1.000 millones de dólares.
} 
Diego Vigna, Lucía Coppari

Nuevos actores en el ecosistema del libro: bookstagrammers argentinas y la recomendación digital de literatura contemporánea

específica de procesamiento de datos, los cuales se producen de manera incesante, se conectan y forman redes (Hui, 2017). Esta gramática supone también el "pasaje del continuum temporal al espacio discreto" (Auroux, 1994, como se cita en Hui, 2017, p. 89). En esto reside una clave para el análisis documental. La fragmentariedad de las publicaciones analizadas no es un atributo, sino una condición del objeto, por la estructura granular y la representación numérica inherentes a todo objeto digital (Manovich, 2005), y repercute en las decisiones tomadas por los productores de contenidos. A su vez, esa fragmentariedad contrasta con la herencia impresa.

En este sentido, analizar publicaciones de Instagram exige precisiones según las características de la plataforma. Lanzada en 2010 como una aplicación para teléfonos móviles, su interfaz permite capturar, editar y publicar imágenes, acompañarlas de otros elementos y ver contenidos de contactos, comentarlos, compartirlos y rastrear imágenes a través de herramientas de búsqueda (Manovich, 2017); es decir, apela, desde un punto de partida visual, a interactuar con otros en un espacio centralizado. Instagram se diferencia de otras redes sociales porque nació pensada para teléfonos móviles - con la fotografía como disparador- y representa un cambio de época en términos de crear y compartir imágenes "sobre la marcha", como afirmaron sus creadores (Manovich, 2017).

En esta línea, Instagram también ha alimentado la iniciativa de capturar la cotidianeidad de usuarios lectores sobre la base de experiencias compartidas. Estos recomiendan libros informalmente desde la producción de imágenes, como quien le habla a un par. El análisis se complejiza necesariamente cuando las comunidades crecen y sus prácticas se montan en las dinámicas de producción y circulación del libro.

Respecto a la interfaz de la plataforma, el contenido del timeline en Instagram -en el que aparecen los posts que el algoritmo de la plataforma considera relevantes para cada usuario según sus rutinas de navegación- es organizado por el carácter que prioriza los contenidos audiovisuales para lograr visibilidad, ya sean imágenes, videos o historias (Ig Stories). Los usuarios -individuales o colectivos- que recomiendan lecturas, autores, sellos colocan necesariamente a estas unidades de contenido documental como centro de atención. Ese impacto es complementado por textos y enlaces a otros nodos de la web, todo lo cual se adecua al funcionamiento estandarizado del medio: las fotografías o videos se presentan como parte de un flujo continuo de información en el que la referencia temporal no es decisiva, como sí sucede, por ejemplo, en Facebook o Twitter: en Instagram, el efecto de lo que ve el usuario, cuando accede a publicaciones de otros, remite a una coexistencia o estado contemporáneo de datos en el que fotos, videos o historias aparecen al mismo tiempo, más allá de sus singularidades y referencias temporales (Manovich, 2013). 
Austral Comunicación

Volumen 9, número 2 (Diciembre de 2020): 349-373. ISSN 2313-9129

En la introducción destacamos la rápida multiplicación de cuentas de Instagram dedicadas a recomendar y reseñar libros. Aquí caracterizaremos este fenómeno involucrado con la difusión, circulación y comercialización de libros en papel a partir de cuatro proyectos que se especializan en comentar obras de literatura contemporánea -mayormente argentina- y que seleccionamos según tres criterios específicos para la delimitación del corpus: 1) popularidad de las cuentas (describimos y analizamos los proyectos que cuentan con mayor número de "seguidores"); 2) actividad regular de las cuentas en la plataforma (publican permanentemente posts e historias); y 3 ) producción paralela de eventos offline (vínculo concreto que establecen los bookstagrammers, o sus proyectos, con otros agentes y actividades propias del campo literario y editorial local). A partir de lo anterior, las cuentas seleccionadas son: "La gente anda leyendo", "Decime un libro", "Dime qué lees" y "Leer argentinos".

Hemos relevado y observado más de 100 posts y videos de Instagram TV (IGTV) realizados durante los periodos comprendidos de noviembre a diciembre de 2019 y de enero a marzo de 2020. De los posts relevados, aproximadamente el $60 \%$ ha sido considerado para el análisis, siguiendo los interrogantes del trabajo, a partir de las tres categorías que se describen a continuación. Las unidades de contenido en formato historia (stories), por su parte, se visualizaron primero en simultáneo, aunque esta serie fue sistematizada a partir de su archivo en destacadas.

Para la descripción y el análisis de los posts hemos definido tres categorías, que responden a la naturaleza de los objetos digitales estudiados, a la interfaz y las funciones definidas por la plataforma y a la observación de las cuatro cuentas que orientaron los interrogantes. De este modo, las unidades de contenido abordadas respondieron a: 1) construcción de la enunciación observada en cada proyecto (con énfasis, articulado por el planteo del objeto, en elementos vinculados a la definición de un yo público cotidiano, a estrategias discursivas centradas en las formas de establecer o no jerarquías entre autores, editores, libreros, lectores); 2) modalidades y estrategias reconocibles en la utilización de las funciones de la plataforma; y 3) modalidades y estrategias reconocibles en las interacciones de las bookstagrammers estudiadas con comunidades de usuarios-lectores.

Teniendo en cuenta estas definiciones, y siguiendo los posicionamientos de Verón (2013) y García Canclini (2009) respecto a las categorías de lectores, espectadores y usuarios, para la recolección de datos también hemos adecuado premisas de la etnografía para internet que desarrolló Christine Hine (2004, 2015), pertinentes para articular la observación y la interpretación de datos en el funcionamiento dinámico de las redes sociales. El método observacional, conjugado con el análisis documental, permite la interrogación acerca de cómo afrontar la relación con los objetos digitales y las interacciones en red, y cómo construir una perspectiva analítica desde el lugar de 
Diego Vigna, Lucía Coppari

Nuevos actores en el ecosistema del libro: bookstagrammers argentinas y la recomendación digital de literatura contemporánea

investigador-usuario teniendo en cuenta lo que Hine (2004) llamó las "creencias acerca de Internet y sus propiedades" (p. 17) que modelan experiencias, prácticas y relaciones tramadas online, y que dan cuenta de subjetividades expuestas en el contexto de redes. Para Hine (2004), las redes sociales constituyen comunidades de prácticas de conocimiento, lenguaje y bienes compartidos; una definición de "comunidad" que se sustenta más en prácticas compartidas que en condiciones físicas (p. 59) y en la consideración de internet como -entre otras cosas- un artefacto cultural creado por personas concretas, para fines concretos, en contextos definidos. En este sentido, estructuramos la observación, la interacción con las cuentas y la recolección de datos a partir de premisas inherentes al objeto estudiado, como describió Hine (2015): la exploración del campo analítico a partir de su construcción fluida y emergente, que se manifiesta en instancias de uso específicas; la consideración de todo fenómeno inserto en internet como una experiencia cotidiana que impone, junto a la observación, un carácter reflexivo de las interacciones, formas discursivas y vínculos o ajenidades entre prácticas y representaciones del espacio; y la advertencia siempre presente de la multiplicidad, en el sentido de que no hay una sola experiencia de los fenómenos online, lo que implica diversas prácticas de creación de sentidos (pp. 86-88).

\section{Resultados: qué y cómo recomiendan las bookstagrammers argentinas}

"La gente anda leyendo", cuenta gestionada por la comunicadora y actriz Maru Drozd, es una de las que recoge mayor popularidad entre lectores-usuarios en Argentina (66.500 seguidores). El nombre es una versión más del reconocido proyecto "La gente anda diciendo", que solo en Instagram cosecha más de 1,5 millón de seguidores."La gente anda leyendo" se autodefine como "recomendador \& club de lectura", y en tres años ha conformado a su alrededor una comunidad lectora a través de diferentes propuestas. Una de ellas es "la foto loca de los viernes", segmento en el que colabora Sebastián Lidijover -exlibrero, promotor de libros y prensa editorial-, y muestra la portada de un libro colocada en una escena -por lo general, una librería de la ciudad de Buenos Aires- construida para dar continuidad real y "vida" a la imagen. Además, la cuenta publica videos con recomendaciones de libreras o respuestas a consignas lectoras por parte de escritores reconocidos: Rosario Bléfari, Santiago Llach y Guillermo Martínez fueron algunos de ellos en el periodo abordado. También participan actores o periodistas, figuras conocidas en los medios informativos y de entretenimiento. Se evidencia que la presencia de personajes que gozan de repercusión o celebridad en diferentes ámbitos traccionan el crecimiento y posicionamiento del espacio de recomendación. Por su parte, la incursión del proyecto en la plataforma Youtube fue con la

Se puede consultar el perfil de la cuenta en: https://www.instagram.com/lagenteandaleyendo/. 
creación de un canal de entrevistas a escritores que Maru Drozd realizó junto al actor -y también escritor- Gonzalo Heredia durante 2018. La primera entrevista, realizada a Fabián Casas, superó las 10 mil visualizaciones. Más recientemente, "La gente anda leyendo" formó un club de lectura que se inició en la virtualidad y derivó en encuentros presenciales y periódicos en bares o librerías, eventualmente con la participación del escritor o escritora del libro que los convocaba. Los libros reseñados o las lecturas propuestas para el club suelen ser novelas breves o cuentos editados por sellos argentinos, como Bajo la luna, Eterna Cadencia, Odelia, Sigilo, Entropía, Compañía Naviera Ilimitada y Godot, entre otros. La cuota de poesía se nutre del posteo ocasional de un poema y la reseña que acompaña y contextualiza la pieza. En todos los casos, la comunidad de lectores es interpelada con alguna cita y/o pregunta relacionada con el tema o el autor en cuestión e interactúa a través de los comentarios, casi siempre referidos al gusto por las obras o a experiencias subjetivas disparadas por la lectura.

"Decime un libro"10 es una cuenta gestionada por Rosario Pozo Gowland, abogada, quien comenzó hace dos años a desarrollar su afición en la web. Actualmente, el número de usuarios que la siguen en Instagram supera los 35 mil. Una parte de esta concurrida comunidad participa de un club de lectura virtual a través de transmisiones en vivo (Instagram Live) convocadas por la gestora del espacio. Las reseñas y las propuestas para la lectura compartida por el club son en su mayoría de narrativa o ensayo publicados por editoriales argentinas como Godot, Blatt \& Ríos, Sigilo, Odelia, Factotum, Mardulce y Fiordo, entre otros sellos relevados. Por su parte, entre las imágenes de portadas de libros con sus respectivas "reseñas", se cuelan también imágenes que muestran situaciones de lectura en diferentes escenarios, acompañadas por alguna reflexión sobre la práctica o el anticipo de la propuesta para el club. Si bien el proyecto se originó en Instagram, en paralelo se desarrolló un sitio web ${ }^{11}$ para la participación de la comunidad en la compraventa de libros usados y la venta de remeras y otros artículos con inscripciones bibliófilas (una suerte de merchandising derivado de las obras y las figuras autorales). Además, "Decime un libro" tiene su versión podcast en Spotify, con episodios dedicados a los libros leídos por el club. Acompañada por su hermano, quien colabora en la producción de contenido, la gestora de la cuenta presenta la lectura de cada obra, ofrece información sobre el autor y la editorial e intercambia interpretaciones y sensaciones sobre la trama en cuestión.

"Dime qué lees"12 es la cuenta de Instagram gestionada por Brenda Algozino, estudiante de Letras en la Universidad de Buenos Aires. A lo largo de tres años de actividad, la cuenta superó los 16 mil seguidores. En la descripción, la gestora del espacio

\footnotetext{
${ }_{10}$ Se puede consultar el perfil de la cuenta en: https://www.instagram.com/decimeunlibro/.

11 Se puede consultar sitio web en: https://www.decimeunlibrostore.com.ar/.

12 Se puede consultar el perfil de la cuenta en: https://www.instagram.com/dimequelees/.
} 
Diego Vigna, Lucía Coppari

Nuevos actores en el ecosistema del libro: bookstagrammers argentinas y la recomendación digital de literatura contemporánea

asume como objetivo "contagiar ganas de leer" y, a través de diferentes posts e historias, se reconoce fanática de los escritores argentinos Martín Kohan -sobre cuya obra dicta talleres virtuales de lectura- y Mariana Enríquez. Las recomendaciones y reseñas son mayormente de narrativa, de escritores argentinos o traducciones editados por sellos como Blatt \& Ríos, Odelia, Fiordo, Bajo la luna, Interzona y Leteo. Por lo general, los textos que acompañan las imágenes o videos finalizan con una pregunta dirigida a los seguidores para indagar sobre la lectura de la obra en cuestión, situaciones semejantes a la narrada o a determinados hábitos lectores. Incluso, "Dime qué lees" inauguró una sección dedicada a compartir recomendaciones o reseñas que envían algunos miembros de esta comunidad. Se puede revisar un ejemplo representativo en la Figura 1, tanto del perfil enunciador (primeras personas que apelan a la descripción de tramas y a las consideraciones subjetivas) como de las estrategias de difusión. En esta línea, comercializa un "Diario de lecturas", en el que se pueden "fichar" los libros leídos y llevar un registro para ordenar y planificar la actividad. También lanzó una serie de videos titulada "Mi odisea en Puan", en la que Algozino refiere su tránsito por la carrera de Letras. Estas y otras tantas publicaciones constituyen "episodios" sobre su vida como lectora y estudiante. Más recientemente, la joven devino en booktuber: primero creó un canal junto a su colega bookstagrammer "Agus recomienda", denominado "Chicas de Letras"; luego, asumió la tarea en el canal de la reconocida librería, distribuidora y editorial Waldhuter, que también publica una revista digital.
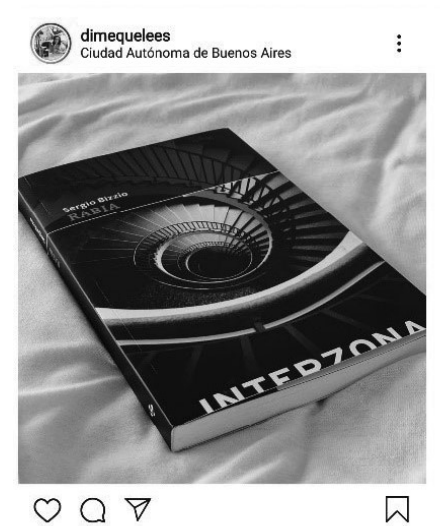

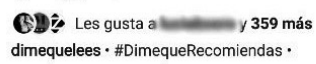

Finalmente estrenamos esta nueva sección! Siempre recibo recomendaciones de sus libros y autores avoritos $y$ cuando quiero elegir un nuevo lectura $\mathrm{me}$ cuesta recordarlos. Por ese motivo, me propuse in

"Rabia" de Sergio Bizzio (@interzonaeditora ) recomendado por @pablo_nardi:

Es una novela corta, atrapante, y un clásico novedad (a veces uno se cansa de seguir el incierto curso de las modas), Bizzio es un crack y tiene un estilo muy particular, como todos sus compañeros de la extinta revista Babel (Alan Pauls, Daniel Guebe Chitarroni, etc). Además es muy gracioso (hay quen dicen que si libro no te hace refr aunque un tipo que después de cometer un crimen, se que varios años de polizonte en una casa muy grande suficiente como para que sus dueños no se den cuenta de que alguien más vive ahí. Aclaración: Rabia fue publicada 15 años antes que Parasite.

글 Voy a reconocer que una de las cosas que más me convenció de la recomendación fue el hecho de que Rabia no se trata de una novedad, aunque eso no$$
\text { O }
$$

Rabia no se trata de una novedad, aunque eso no significa que no sea un libro que se comenta muchisimo e incluso aparece seguido en las redes perdurar en el tiempo y provocar que se sige a libro ando una historia, aún 15 años despu publicación.

Al leer a Bizzio, no fue dificil encontrar la respuesta. Rabia te deja en vilo en cada capítulo y de alguna manera te empeñás en construir salidas posibles para su personaje, José María, aunque en el fondo cada idea parezca solo un espiral de pensamiento. La relación entre Rabia y Parasite seguirá pendiente a que aún no vi la película. No me decido si verla o

- ¿Les gusta esta sección? Pueden mandar su ecomendación por mail a hola@dimequelees.com.ar Ver los 32 comentarios

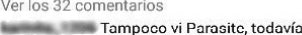
Rabia es excelente, una historia de adavia. particular, que te tiene en vilo y con una sensación claustrofóbica durante todo el relato. De mis favoritos

dimequelees :- Gran lectura! Ahora quiero leer algo más de Bizzio

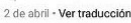

今

Figura 1. Recomendación en Dime qué lees de una novela de Sergio Bizzio, a cargo de un colaborador. (Fuente: Instagram, obtenido el 12 de mayo de 2020). 
Desde el espacio en Cuaderno Waldhuter, ${ }^{13}$ Algozino también ofrece reseñas y consejos para que los lectores gestionen su tiempo y optimicen su experiencia, algo que no es propio solo de esta cuenta, sino que se manifiesta en otros casos. Como se ve en la Figura 2, este tipo de recomendaciones han propiciado incluso estrategias comerciales sostenidas por el formato del post en Instagram, como el caso de Rosario Pozo Gowland y la aplicación para teléfonos móviles Toldy ${ }^{14}$, que ofrece optimizar el tiempo libre de los usuarios a partir de una selección de textos que pueden leerse según la disponibilidad. Esto representa el despliegue de nuevos hábitos de lectura que propician, a su vez, nuevas prácticas de consumo: Toldy se basa en no hacerse tiempo para leer (la experiencia focalizada), sino en leer en los huecos que produce el movimiento cotidiano. Como indica su eslogan: "Micro momentos de lectura para que disfrutes donde y cuando quieras. Leé en el tiempo que tenés”.
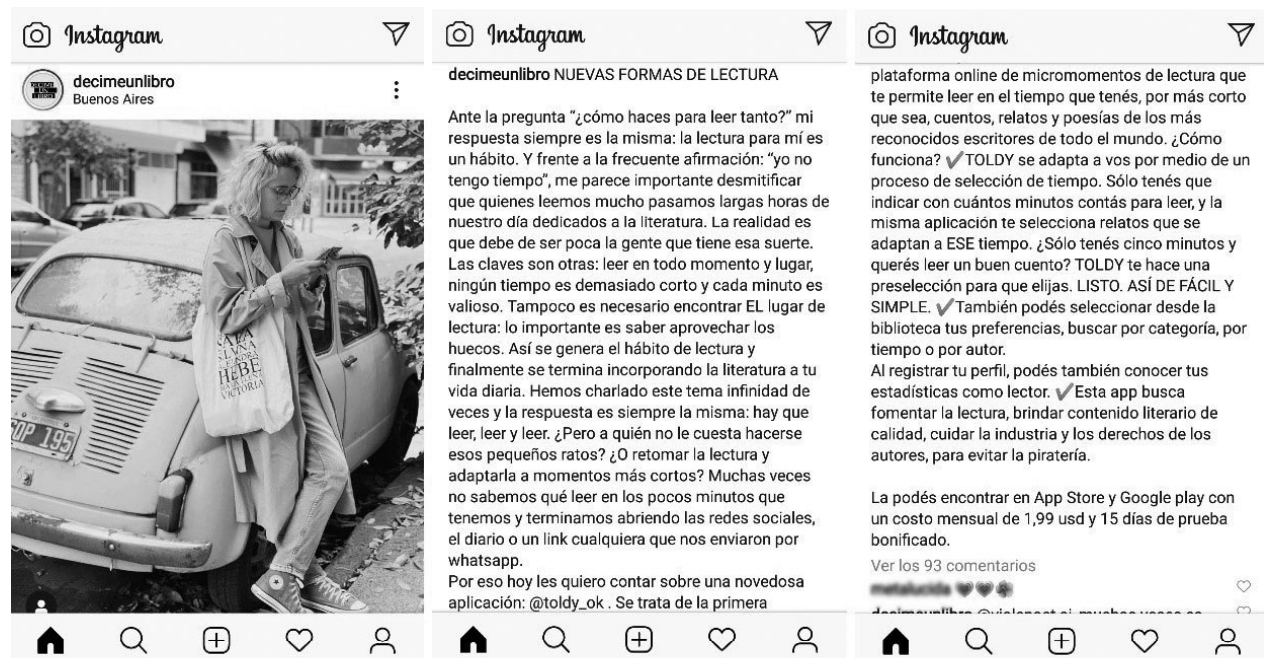

Figura 2. Publicidad de la aplicación para teléfonos Toldy en la cuenta "Decime un libro". La gestora de la cuenta interpela a los lectores e incluye una foto de sí misma como disparador. (Fuente: Instagram, obtenido el 26 de abril de 2020).

"Leer argentinos", ${ }^{15}$ por último, es el proyecto de Florencia Savarino, licenciada en Letras, y de Cecilia Di Tirro, productora de radio y televisión, que lleva dos años de actividad en Instagram y alcanza los 12.300 seguidores. La propuesta consiste en publicar reseñas de narrativa, poesía y también ensayo, en su mayoría de escritores argentinos o latinoamericanos publicados por editoriales como Alto pogo, Bajo la luna, Madreselva, Santos locos, Mardulce, Paisanita, Godot y Añosluz. Una iniciativa distinta de este espacio es el lanzamiento semanal, a través de las historias, de los "lunes de encuesta":

\footnotetext{
13 Se puede consultar el sitio de la revista en: https://cuadernowhr.com/.

${ }_{14}$ Se puede consultar el perfil de Instagram del emprendimiento en: https://www.instagram.com/toldy_ok/.

15 Se puede consultar el perfil de la cuenta en: https://www.instagram.com/leerargentinos/.
} 
Diego Vigna, Lucía Coppari

Nuevos actores en el ecosistema del libro: bookstagrammers argentinas y la recomendación digital de literatura contemporánea

se propone a los seguidores la resolución de preguntas cerradas con dos opciones de respuesta cada una, que indagan en las preferencias sobre determinados escritores, géneros y hábitos de lectura y que apelan a diferentes recursos humorísticos. Bajo esta misma modalidad, proponen los "viernes de poesía", con consignas de escritura -por lo general, a partir de un tema, un poema o un verso disparador- dirigidas a la comunidad de seguidores. Por ejemplo, un "poema de odio", un poema sobre la lluvia, un haiku, un poema cuyas palabras comiencen con cada una de las letras de otra palabra determinada. Las consignas son variables y, en ocasiones, consistieron en compartir una foto o un video recitando algún poema favorito. Las producciones que envían los usuarios participantes son publicadas en las historias posteriores. Adicionalmente, las gestoras de "Leer argentinos" ofrecen talleres presenciales y virtuales de escritura y lectura -por ejemplo, de cuentistas latinoamericanas o cuentistas argentinos-, y periódicamente programan encuentros en bares que complementan la actividad online. Por ejemplo, al momento de la redacción de este artículo debutaron con "La previa literaria”, una propuesta pensada para compartir lecturas y tragos de coctelería.

En términos cuantitativos, el promedio de publicaciones mensuales de cada una de las cuentas analizadas varía en un amplio rango: entre 5 y 12, y el tipo de publicaciones, como se aprecia en las referencias anteriores, también es versátil. En "Leer argentinos" se publica de manera más esporádica y una mayor proporción de reseñas (más del 50\%), mientras que "La gente anda leyendo", "Decime un libro" y "Dime qué lees" tienden a publicar más frecuentemente y a diversificar los contenidos. En estos casos, aproximadamente un tercio de las publicaciones son estrictamente reseñas de libros. En "La gente anda leyendo", estas reseñas se intercalan con imágenes de registro del club de lectura, "la foto loca de los viernes", los videos de lectores "reconocidos", los poemas y algunos memes. En "Decime un libro", además de las reseñas, se publican imágenes como las descritas: episodios o escenas de la gestora de la cuenta durante un momento de lectura, paisajes urbanos y naturales; todas imágenes acompañadas por un poema, un fragmento de libro o una reflexión surgida a partir de la lectura. Otras publicaciones, como se señaló, remiten a la lectura del club, al podcast de la cuenta o a la tienda virtual. En "Dime qué lees" ganan protagonismo las imágenes de la biblioteca hogareña de la gestora de la cuenta ofreciendo consejos prácticos en clave literaria: cómo leer más, cómo elegir la próxima lectura, cómo registrarlas, etc., en consonancia con su perfil booktuber. Por último, en "Leer argentinos", el complemento de las reseñas son mayormente avisos y registros de los talleres de lectura y de "La previa literaria".

$\mathrm{El}$ análisis de las publicaciones de estos proyectos permite identificar propiedades que remiten -desde las categorías definidas- tanto en términos discursivos (Verón, 2013) como sociotécnicos (Manovich,2017) a una gramática específica de producción y convivencia en el medio: operaciones o "reglas" que dan forma a una variante de 
discursos, tomando en cuenta las especificidades del lenguaje en uso y las condiciones de recepción. ${ }^{16}$ En relación con las publicaciones impresas que anteceden a la breve, pero intensa, historia de intervenciones digitales, se puede distinguir una característica que divide las aguas respecto a la labor crítica en medios tradicionales, en los que el desfase constitutivo entre producción y reconocimiento se institucionaliza y amplifica (Verón, 2013) y la circulación tiene una dirección descendente: de pocos enunciadores que poseen una serie de competencias a múltiples receptores. En cambio, en el sistema de medios conectivos, y atendiendo a los cambios señalados, la circulación es primeramente horizontal: de unos usuarios-lectores a otros que comparten sus intereses. En los casos abordados, los discursos alcanzan mucha repercusión por la cantidad de seguidores que tienen las cuentas y, ocasionalmente, hasta se reproducen o se instalan en los medios masivos, ${ }^{17}$ lo que impacta en la visibilidad - ¿prestigio digital?- de los enunciadores y en los flujos de circulación posteriores.

Las bookstagrammers analizadas parecen reforzar esa simetría entre producción y reconocimiento valiéndose de reseñas breves -de entre 300 y 400 palabras aproximadamente-, que carecen de apelaciones a saberes especializados, referencias teóricas o posiciones heredadas de la tradición crítica. Y entre los puntos más relevantes para el estado actual de las estrategias de difusión y circulación de libros es que construyen un yo público cotidiano con características y prácticas similares a las de sus seguidores en reconocimiento: la organización de la biblioteca hogareña, las mascotas o el café acompañando la lectura, las dificultades para dedicar tiempo a este hobby compartido, la pasión sin restricciones por algún escritor, género o editorial, los recorridos por librerías, ferias y eventos literarios. En todo el abanico temático que abordan, la imagen se ofrece como unidad de referencia y disparadora de las intervenciones de los usuarios. Luego, las dinámicas de taller, los encuentros periódicos o clubes de lectura -que parecen diluir la figura de autoridad competente- consolidan esa proximidad.

De modo que si bien el leitmotiv de un bookstagrammer es reseñar libros, en Instagram predomina el orden de lo icónico, esto es, lo que se ve.Y por ello las imáge-

\footnotetext{
${ }_{16}$ Manovich (2013) destaca cómo las culturas de la imagen en medios como el analizado van más allá de las tecnologías en bruto, e incluso de las formas en las que las personas usan estos medios, para hablar también de los sistemas y convenciones y técnicas que definen los temas, narraciones, edición, composiciones y otras características de la producción que nace de contenidos visuales. Un "lenguaje visual", de hecho, representa para el autor esas elecciones sistemáticas que insisten para ser relevantes en términos de repercusión, tanto para los creadores como para los seguidores de las cuentas.

17 En abril de 2018, en el marco de la apertura de una nueva edición de la Feria Internacional del Libro de Buenos Aires, la Revista editada por el diario La Nación publicó un artículo de portada titulado "Lectores influyentes: los nuevos protagonistas del mundo literario". La imagen elegida para esa portada fue la de Gonzalo Heredia cubierto por libros. Además de la entrevista al colaborador de "La gente anda leyendo", la revista difundió el testimonio de cinco influencers que recomiendan lecturas desde las redes sociales. Desde la actriz Carla Quevedo o la cantante Julieta Venegas hasta el jugador de fútbol Ignacio Bogino y el booktuber adolescente Augusto Funes. Entre ellos, figuró Maru Drozd, responsable de “La gente anda leyendo". El artículo es uno más de los que vienen noticiando estas prácticas. Las particularidades del caso tienen que ver con la popularidad de Gonzalo Heredia, el lugar destacado que se le dio en la revista y el tratamiento del fenómeno cuando empezaba a consolidarse en el país.
} 
Diego Vigna, Lucía Coppari

Nuevos actores en el ecosistema del libro: bookstagrammers argentinas y la recomendación digital de literatura contemporánea

nes de portadas de libros o de situaciones de lectura generan impacto o identificación, para ganar likes y capturar el interés y la atención de los usuarios que chequean el feed. "La foto loca de los viernes" que publica cada semana "La gente anda leyendo" constituye un ejemplo cabal de lo anterior. Esa foto suele ser reposteada por la librería, la editorial o el autor convocado. Así también, cada bookstagrammer afirma una estética visual distintiva, una marca de sí, al decir de Groys (2014): la elección de algunos espacios que se muestran de manera recurrente, los encuadres fotográficos que varían en función de las características del post, la tipografía utilizada y los colores y/o los filtros de la interfaz utilizados, entre otros aspectos. Estas elecciones se estandarizan en pos de reforzar la identidad de cada proyecto a medida que la comunidad crece.

Dentro de la tercera categoría de análisis, el canal de video de IGTV, las transmisiones en directo y las historias con encuestas o preguntas abiertas son recursos utilizados permanentemente, dado que habilitan modos de interactividad que contribuyen a generar discurso por parte de los usuarios-lectores e incluso impactan sobre las estrategias de enunciación y los libros a reseñar. Un ejemplo es el uso de las historias para los "lunes de encuesta" y los "viernes de poesía" de la cuenta "Leer argentinos". Las responsables comparten las respuestas con las producciones, lo que muestra la participación activa de un gran número de seguidores. En el caso de "Decime un libro", se utilizan las transmisiones en directo para reunir a la comunidad del club de lectura y compartir apreciaciones sobre las obras. Al momento de la redacción de este artículo, "La gente anda leyendo" innovó con el concepto de "vivo fest" en el marco de la pandemia de COVID-19. La propuesta consistió en realizar un "festival de recomendaciones" y convocar, a través de transmisiones en directo en diferentes horarios, a escritores, periodistas, músicos y actores que oportunamente dialogaron con Maru Drozd y sugirieron lecturas. ${ }^{18}$

Las comunidades, colectivos de usuarios-lectores y, a su vez, espectadores-internautas también presentan particularidades propias en Instagram. Desde la perspectiva de Verón $(1997,2013)$, estos colectivos se constituyen por la articulación identitaria de un conjunto de individuos a partir del funcionamiento de las estrategias enunciativas en producción y de las gramáticas de reconocimiento de los discursos. Pero ¿quiénes forman parte de los colectivos alrededor de las bookstagrammers referenciadas? ¿Qué gramáticas de reconocimiento ponen en juego? A partir de la exploración de los comentarios, las historias y los reposts, una primera respuesta a estos interrogantes es que no conforman una unidad homogénea, sino que se trata de una multiplicidad: desde usuarios anónimos que desarrollan y expresan su interés por la lectura y, en particular, por las que propone determinada bookstagrammer, hasta lectores "profesionales"

${ }_{18}$ En el canal IGTV se encuentran algunos registros: https://www.instagram.com/lagenteandaleyendo/channel/. 
(Lahire, 2004), como escritores, editores, libreros y otros. Por lo tanto, las gramáticas de reconocimiento son plurales como la misma lógica conectiva.

Los seguidores anónimos o amateurs, que forman colectivos a partir del fenómeno hipermediático descrito, muestran diferentes niveles de identificación y compromiso con los proyectos: desde comentarios que expresan gratitud o empatía, pasando por el cumplimiento de consignas propuestas hasta la participación activa en clubes de lectura o talleres, tanto en versiones online como offline.

Todas las cuentas analizadas hacen uso de la función de etiquetado: tanto escritores como editoriales son referenciados e interpelados en cada publicación a través de este recurso que ofrece la plataforma, dentro de la lógica conectiva. De tal manera, captan esos likes y, ocasionalmente, comentarios en las publicaciones. Los lectores profesionales se implican con uno o varios proyectos por las posibilidades de circulación que se abren, por lo tanto, hacen llegar novedades, entablan vínculos comerciales o programan actividades con las bookstagrammers, repostean las publicaciones en las que son convocados e incluso, en ocasiones, forman parte de los contenidos o participan de clubes de lectura. ${ }^{19}$ Se pueden citar, a modo de ejemplo, los videos que publica "La gente anda leyendo" con entrevistas a diferentes actores de la cadena del libro, ofreciéndoles un espacio de circulación de obras y contenidos y legitimando el propio proyecto ante el colectivo de seguidores. La relación entre Brenda Algozino, de "Dime qué lees", y el espacio Waldhuter muestra una de las aristas comerciales del fenómeno, además de la venta de productos o el dictado de talleres.$^{20}$ Así, también, los intercambios se materializan a través de la participación de las bookstagrammers en la programación de la Feria de Editores (FED ${ }^{21} \mathrm{o}$ de Zona Futuro en la Feria Internacional del Libro de Buenos Aires, con el auspicio de editoriales independientes que tienen sus estands en el evento. En definitiva, en los últimos años y con mayor recurrencia, los actores de la cadena del libro buscan y construyen aliados en -y a condición de- el trabajo a primera vista informal, pero sostenido, de estos nuevos protagonistas y mediadores en el vínculo entre obras y consumidores desde las premisas hipermediales de las redes sociales.

\section{De la crítica literaria a la recomendación: herencia de medios e influencia de redes en la circulación de libros}

Las instituciones más atentas a la crítica, difusión y promoción de obras literarias en Argentina, sobre todo durante el siglo XX, han sido la academia y el periodismo

\footnotetext{
19 Por ejemplo, la participación de las escritoras Paula Vázquez y Adriana Riva en el club de lectura de "La gente anda leyendo".

${ }^{20}$ La tienda virtual de "Decime un libro" o los talleres coordinados por las gestoras de "Leer argentinos" constituyen algunos ejemplos

${ }^{21}$ La Feria de Editores es organizada desde 2013 por los responsables de la editorial Godot. Los editores participantes atienden sus propios estands y colaboran en la programación de las actividades.
} 
Diego Vigna, Lucía Coppari

Nuevos actores en el ecosistema del libro: bookstagrammers argentinas y la recomendación digital de literatura contemporánea

cultural e intelectual. En estos marcos, las revistas y los suplementos culturales fueron los formatos que encauzaron el discurso crítico más álgido y hoy continúan ejerciendo el papel cada vez más restringido de alimentar el espacio intelectual y literario de producción de ideas. La historia de las revistas y los suplementos transcurrió durante décadas articulando diálogos, oposiciones y cuestionamientos recíprocos, basados en fuertes posicionamientos estéticos e ideológicos. El aparato crítico se materializó en esas publicaciones dedicadas a actualizar y dar nervio a los debates públicos sobre la edición y la recepción de obras (Vigna, 2015). Las revistas literarias permitieron, según varios autores (Altamirano y Sarlo, 1983; Patiño, 2017), establecer una pintura consistente del campo literario local a partir del análisis de modos de producción y agrupamientos, de laboratorios ideológicos o estéticos, y fueron concebidas como plataformas de legitimación de autores y obras (Sarlo, 1992).

¿Cómo se explica, entonces, la mutación parcial de ese aparato crítico de discusión y legitimación de obras hacia un ambiente caracterizado por las estrategias de recomendación en plataformas digitales? ¿Cómo comprender, o insertar en contexto, la emergencia de una ética cotidiana en la circulación de libros, informal y multimedial? Si se concibe a la literatura como parte de un proceso social, se puede examinar en esta clave el derrotero reciente de sus expresiones críticas. Hernaiz (2012), por ejemplo, propuso un recorrido partiendo de la forma revista. En la década del 90, destacó la pérdida de influencia del discurso literario en las reverberaciones sociales, que arrastraba una herencia nítida desde los 60 hasta el fin de la última dictadura. En ese contexto, según Hernaiz (2012), las estrategias de distinción de los medios de difusión de obras se basaban en una oposición a las agendas de los medios masivos de comunicación. Las revistas buscaban lectores en torno a diagnósticos del presente y al cuestionamiento de tradiciones, intentando imponer nuevas lecturas e inscribir operaciones estéticas atadas a la coyuntura. Si la literatura comenzó a "funcionar" como un campo cada vez más restringido frente al avance neoliberal y de industrias del entretenimiento, la crítica se dedicó a una consideración de la escritura, a pesar de todo, como modo de defender terreno (Hernaiz, 2012).

Frente a esa pérdida de valor específico del discurso literario en el orden social, tan marcado a fin de siglo, Hernaiz (2012) describe un posterior ensanchamiento de lo legible que repercutió en las instituciones y en la crítica de obras. Nuevas expresiones narrativas, la presencia desplegada de imágenes y los medios de comunicación en red llevaron a que la crítica debiera generar horizontes alternativos de significación y también nuevos objetos de análisis. De modo que las prácticas literarias y críticas comenzaron a mutar porque así lo hacían las condiciones sociales de producción, a partir del ambiente tecnológico cada vez más omnipresente, la economía en evidente deterioro y la dificultad creciente para publicar por la concentración editorial. 
Los escritores y editores del siglo XXI, necesariamente insertos en un paisaje de conectividad modelado por los flujos de información, buscaron difundir sus obras por todos los medios y actores posibles. A su vez, los espacios de legitimación siguieron encapsulándose: sobrevivieron instancias académicas, algunos críticos y reseñistas en suplementos literarios, y se abrió una oferta atomizada en revistas digitales y blogs de crítica que tienen la recompensa inmediata de la visibilidad, pero que también sufren esa atomización, solo "salvada" cuando las redes sociales centralizan la difusión de contenidos. Buena parte de lo que antes era pensado exhaustivamente desde el derrotero histórico de la crítica de libros hace tiempo se aborda desde el problema de la circulación y las temporalidades digitales.

\section{La circulación como marca de época}

La promoción de obras por parte de usuarios que capitalizan comunidades virtuales -seguidores- desde las redes parece una novedad de aparente relación con lo anterior. Casi siempre se autodefinen como lectores apasionados que buscan compartir experiencias estéticas. El punto que nos incumbe es que aquí intervienen elementos para comprender por qué la crítica no interesa a estos fenómenos de la palabra visibilizada. Uno de ellos es la temporalidad de internet y la naturaleza de los objetos digitales; el otro forma parte de las implicancias sociales de lo que Arfuch (2015) llamó el "giro afectivo", ostensible en la cultura conectiva, esto es, apelar a la cercanía de -y empatía con- pares que son desconocidos por el gusto de la experiencia estética compartida.

Graciela Montaldo (2017) propuso un vínculo entre la noción de "temporalidad" y la de "obsolescencia" para caracterizar a la cultura reconvertida abiertamente en objeto de consumo. Para la autora, hoy los productos culturales son sometidos al mismo régimen de obsolescencia, recambio y novedad que rige a cualquier otra mercancía, algo que, a su vez, demanda un esquema particular de interpretación: la disponibilidad de información y la circulación como dimensiones centrales de lo legible. Por lo tanto, la escritura "dejó de reclamar la complejidad y la sofisticación que la habían caracterizado" (Montaldo, 2017, p. 54) desde mitad de siglo XX hasta el auge neoliberal, para adecuarse a las necesidades contextuales de mayor interlocución: una escritura "más dialógica" (Montaldo, 2017, p. 54). El fenómeno de los bookstagrammers cabría en esa afirmación, dado que, en estas condiciones, incluso las formas de la crítica también se hicieron más legibles al deber adaptarse a la concepción del consumo cultural que reproduce el ecosistema digital (Montaldo, 2017).

Los últimos años evidenciaron una constricción en las tiradas de sellos independientes, como también en las novedades dedicadas a la crítica, de repercusión cada vez más restringida. En ese contexto, la premisa de la circulación de contenidos parece haber abandonado la aspiración de generar un público ampliado -lectores masivos- 
Diego Vigna, Lucía Coppari

Nuevos actores en el ecosistema del libro: bookstagrammers argentinas y la recomendación digital de literatura contemporánea

en pos de cosechar lectores adecuados (Montaldo, 2017). Sin embargo, no deja de ser paradójico que las recomendaciones de bookstagrammers, como así también las de booktubers y bloggers en otras plataformas y formatos -algo que, sin duda, exige abordajes complementarios, como en Albarello, García Luna y Arri (2019)-, apelen a captar lectores adecuados sin negociar el objetivo de difusión: atraer muchísimos seguidores, todos los posibles, para que sus nichos de trabajo se mantengan activos.

Los medios conectivos amplían posibilidades de acceder a los libros e incluso ciertas estrategias para orientarse en la elección de las lecturas, y la lectura en sí misma, en tanto práctica, se trastoca en su sentido tradicional. La lectura en medios digitales es transversal, semántica (por palabras clave), guiada por motores de búsqueda y basada en formas fragmentarias como las que analizamos. Respecto a las nuevas formas de recomendación y difusión de libros, en la web el valor argumentativo, sostén histórico de cualquier ejercicio crítico, tiende a desaparecer en función del tránsito de información: lo importante es que los posts se actualicen y circulen como pulso de la marca de cotidianeidad que observamos en los casos citados.

\section{Conclusiones}

Las crisis del sector editorial siguen acentuando la brecha estructural entre la capacidad productiva y publicitaria de las grandes empresas que explotan herramientas de difusión canónicas (distribución, prensa, eventos, industria del ocio y el entretenimiento) y la heterogeneidad que caracteriza al sector independiente: un paisaje multiforme de estéticas, posicionamientos políticos, materialidades y estrategias de visibilidad y distinción. En este marco, el abordaje de formas interactivas de recomendación en medios conectivos sirve para registrar la evolución de determinados procesos de producción y circulación de libros en las últimas décadas, signados por la convivencia de soportes: una suerte de nueva ética horizontal que comunica el prestigio autoral, la participación de lectores-internautas, las alternativas de comercialización y el componente aspiracional que la web ha vehiculizado (la organización de encuentros y talleres en los que los lectores buscan formarse como autores). Esto último genera, a su vez, un protagonismo cada vez más "aurático" de los editores, que capitalizan una oferta inaudita de obras pugnando por ingresar al circuito del libro.

Las cuentas de bookstagrammers aquí analizadas pueden significar una aproximación a cierta representatividad de los procesos que algunos investigadores han definido como la "ampliación del campo de batalla" de la literatura local (Hernaiz, 2012), signada por la concentración global del capital, los vaivenes económicos y el desarrollo del circuito independiente, cuyos protagonistas son las editoriales, las librerías pequeñas o especializadas y la distribución cooperativa, ayudados por los recursos de la web. En este contexto, como también señaló Rosario Pozo Gowland (como se cita en Menotti, 
Austral Comunicación

Volumen 9, número 2 (Diciembre de 2020): 349-373. ISSN 2313-9129

2018), la conformación de comunidades virtuales en torno al libro da cuenta de notables mutaciones en los modos de acercamiento a las obras y en los hábitos de lectura. El punto más novedoso quizás sean las formas de mediación entre obras y públicos, que traman la experiencia literaria con recursos hipermediales e interactivos y la afirman como consumo desacralizado, "sobre la marcha", según la propuesta original de Instagram: siempre en movimiento.

\section{Referencias}

Albarello, F., García Luna, A. L. y Arri, F. (2019). Los booktubers en el ecosistema del libro y la lectura. Revista Latinoamericana de Estudios Editoriales, (1). Obtenido de http://redeseditoriales.org/OJS/index.php/Releed/article/view/ releed-1-12-albarello-garcia-arri.

Altamirano, C. y Sarlo, B. (1983). Literatura/Sociedad. Buenos Aires: Hachette.

Arfuch, L. (2015). El "giro afectivo". Emociones, subjetividad y política. Designis, (24), 245-254.

Botto, M. (7-9 de mayo de 2012). Esos raros proyectos nuevos. Reflexiones para la conceptualización de las nuevas prácticas editoriales (Ponencia).Memoria académica del VIII Congreso de Teoría y Crítica literaria Orbis Tertius. Facultad de Humanidades y Ciencias de la Educación, Universidad Nacional de La Plata. Obtenido de http:// www.memoria.fahce.unlp.edu.ar/trab_eventos/ev.1584/ev.1584.pdf.

Botto, M. (2014). 1990-2010. Concentración, polarización y después. En De Diego, J. L. (dir.). Editores y políticas editoriales en Argentina (1880-2010) (pp. 219-269). Fondo de Cultura Económica.

Cámara Argentina del Libro. (2020). Informe de producción del libro argentino 2019. Obtenido de https://www.camaradellibro.com.ar/index.php/la-camara/ noticias/30-noticias-cal/3226-informe-de-produccion-2019.

Carlón, M. (2015). Público, privado e íntimo: el caso Chicas bondi y el conflicto entre el derecho a la imagen y a la libertad de expresión en la circulación contemporánea. En Castro, P. C. (org.). Dicotomía público/privado: estamos no camino certo? (pp. 211-232). Maceió: EDUFAL.

Echevarría, S. (2009). El futuro llegó, hace rato. No Retornable, (4). Obtenido de http:// www.no-retornable.com.ar/v4/dossier/introduccion.html.

Ernst, W. (2018). Tempor(e)alities and archive-textures of media-connected memory. En Hoskins, A. (ed.). Digital memory studies. Media pasts in transition (pp. 143155). Nueva York: Routledge.

García Canclini, N. (2009). Lectores, espectadores e internautas. Barcelona: Gedisa.

Groys,B.(2014).Volverse público: lastransformaciones del arte en el ágora contemporánea. Buenos Aires: Caja Negra. 
Diego Vigna, Lucía Coppari

Nuevos actores en el ecosistema del libro: bookstagrammers argentinas y la recomendación digital de literatura contemporánea

Hernaiz, S. (2012). Revistas literarias y lugar social de la literatura en los años noventa. En Rodolfo Walsh no escribió Operación masacre y otros ensayos (pp. 99-127). Bahía Blanca: 17 Grises Editora.

Hine, C. (2004). Etnografía virtual. Barcelona: UOC.

Hine, C. (2015). Ethnography for the Internet. Embedded, embodied and everyday. Londres/Nueva York: Bloomsbury.

Hoskins, A. (2017). Digital memory studies. Media pasts in transition. Nueva York: Routledge.

Hui, Y. (2017). ¿Qué es un objeto digital? Virtualis, 8(15), 81-96. Obtenido de https:// www.revistavirtualis.mx/index.php/virtualis/article/view/221/199.

Kallinikos, J., Aaltonen, A. y Marton, A. (2010). A theory of digital objects. First Monday, 15(6-7). Obtenido de https://firstmonday.org/ojs/index.php/fm/article/ download/3033/2564.

Lahire, B. (2004). Conclusión. Del consumo cultural a las formas de la experiencia literaria. En Lahire, B. (coord.). Sociología de la lectura (pp. 197-198). Barcelona: Gedisa.

Manovich, L. (2005). El lenguaje de los medios de comunicación. La imagen en la era digital. Barcelona: Paidós.

Manovich, L. (2013). Zooming into an Instagram City: Reading the local through social media. First Monday, 18(7). Obtenido de https://firstmonday.org/ojs/index. $\mathrm{php} / \mathrm{fm} /$ article/download/4711/3698.

Manovich, L. (2017). Instagram and Contemporary Image. Manovich.net, Cultural Analytics Lab. Obtenido de http://manovich.net/index.php/projects/ instagram-and-contemporary-image.

Menotti, E. (mayo de 2018). "Decime un libro": nueva forma de ser un bookstagrammer. Clapps. Obtenido de https://www.clapps.com.ar/ decime-libro-nueva-forma-bookstagrammer/.

Montaldo, G. (2017). Ecología crítica contemporánea. Cuadernos de Literatura, (41), 50-61. Obtenido de https://doi.org/10.11144/Javeriana.cl21-41.ecco.

Pariser, E. (2017). El filtro burbuja. Barcelona: Taurus.

Patiño, R. (2017). El ensayismo crítico y la transnacionalización del latinoamericanismo en el Cono Sur (1990-2000). Anales de Literatura Hispanoamericana, (46), 49-62.

Ramsey, D. (2018). Tensions in the interface. The archive and the digital. En Hoskins, A. (ed.). Digital memory studies. Media pasts in transition (pp. 280-301). Nueva York: Routledge.

Rodríguez Ruiz, J. (2018). Del autor junta palabras al autor junta palabras, imágenes, sonidos, interactividades, algoritmos: la gestión literaria en la era (post) digital. La palabra, (32), 19-41.Obtenido de https://doi.org/10.19053/01218530.n32.2018.8159. 
Austral Comunicación

Volumen 9, número 2 (Diciembre de 2020): 349-373. ISSN 2313-9129

Sarlo, B. (1992). Intelectuales y revistas: razones de una práctica. América. Cahiers du CRICCAL, (9-10), 9-16. Obtenido de https://doi.org/10.3406/ameri.1992.1047.

Shum, Y. M. (16 de marzo de 2020). Situación digital, Internet y redes sociales Argentina 2020. Yi Min Shum Xie Social Media. Obtenido de https://yiminshum. com/social-media-argentina-2020/.

Stephenson, N. (2003). En el principio... fue la línea de comandos. Madrid: Traficantes de sueños.

Van Dijck, J. (2016). La cultura de la conectividad. Una historia crítica de las redes sociales. Buenos Aires: Siglo XXI.

Vanoli, H. (2019). El amor por la literatura en tiempos de algoritmos. 11 hipótesis para discutir con escritores, editores, lectores, gestores y demás militantes. Buenos Aires: Siglo XXI/Crisis.

Verón, E. (1997). Esquema para el análisis de la mediatización. Diálogos de la comunicación, (48), 9-17.

Verón, E. (2013). Lógicas sistémicas sociales y socioindividuales. En La semiosis social 2. Ideas, momentos, interpretantes (pp. 291-303). Buenos Aires: Gedisa.

Vigna, D. (2014). La década posteada. Blogs de escritores argentinos (2002-2012). Córdoba: Alción Editora.

Vigna, D. (2015). De la tradición de revistas al mundo virtual. Aproximación a las publicaciones culturales digitales en el campo intelectual argentino de la última década. Pilquen (ciencias sociales), (3), 21-35. Obtenido de http://revele.uncoma. edu.ar/htdoc/revele/index.php/Sociales/article/view/1401/pdf.

Wrede, O. (25 de mayo de 2005). Are blogs different to forums? Details of a global brain. Obtenido de http://wrede.interfacedesign.org/archives/992.html. 